\title{
Progression of Type 2 Helper T Cell-Type Inflammation and Airway Remodeling in a Rodent Model of Naturally Acquired Subclinical Primary Pneumocystis Infection
}

\author{
Pablo A. Iturra, ${ }^{*}$ Diego A. Rojas, ${ }^{*}$ Francisco J. Pérez, ${ }^{*}$ Andrea Méndez, ${ }^{*}$ Carolina A. Ponce, ${ }^{*}$ Paula Bonilla, \\ Rebeca Bustamante, ${ }^{*}$ Héctor Rodríguez, ${ }^{\dagger}$ Caroll J. Beltrán, ${ }^{\ddagger}$ and Sergio L. Vargas*
}

From the Microbiology and Mycology Program* and the Anatomy and Developmental Biology Program, ${ }^{\dagger}$ Biomedical Sciences Institute, and the
Gastroenterology Division, ${ }^{\ddagger}$ University Hospital, University of Chile School of Medicine, Santiago, Chile

\author{
Accepted for publication \\ October 19, 2017. \\ Address correspondence to \\ Sergio L. Vargas, M.D., Pro- \\ grama de Microbiología y \\ Micología, Instituto de Ciencias \\ Biomédicas, Facultad de \\ Medicina Universidad de Chile, \\ Independencia 1027, Santiago \\ 8380453, Chile. E-mail: \\ svargas@med.uchile.cl.
}

\begin{abstract}
Subclinical primary Pneumocystis infection is the most common pulmonary infection in early infancy, making it important to determine whether it damages the lung. Pneumocystis peaks at 2 to 5 months of age, when respiratory morbidity coincidently increases. We have documented that Pneumocystis increases mucus production in infant lungs, and animal models reveal lung lesions that warrant characterization. Herein, immunocompetent rats infected at birth with Pneumocystis by cohabitation, to resemble communityacquired infection, underwent lung assessments at 45, 60, and 75 days of age. Lungs fixed by vascular perfusion to prevent collapse during necropsy were used for morphometry evaluations of mucus production, airway epithelial thickening, perivascular and peribronchiolar inflammation, and structural airway remodeling. Changes in these histologic features indicate lung disease. Selected immune markers were assessed in parallel using fresh-frozen lung tissue from sibling rats of the same cages. Sequential activation of NF- $\kappa B$ and an increased Gata3/T-bet mRNA level ratio, consistent with a type 2 helper T-cell-type inflammatory response, and subacute fibrosis were recognized. Therefore, documenting subclinical Pneumocystis infection induces lung disease in the immunocompetent host. Taken together with the peak age of primary Pneumocystis infection, results warrant investigating the clinical impact of this often subclinical infection on the severity of respiratory diseases in early infancy. This model can also be used to assess the effects of airway insults, including coinfections by recognized respiratory pathogens. (Am J Pathol 2018, 188: 417-431; https://doi.org/10.1016/j.ajpath.2017.10.019)
\end{abstract}

Whether subclinical infections induce lung damage is poorly understood and needs clarification because lung damage by subclinical pathogens may affect the clinical expression of overt respiratory pathogens and may also favor respiratory disease. ${ }^{1}$ Mild infections and other pulmonary insults stimulate innate and adaptive immunity. They aggravate viral infections and eventually lead to chronic lung disease, ${ }^{2-5}$ implying it is vital to understand the pathologic burden and potential clinical implications of mild subclinical infections. For example, frequent subclinical infections as copathogens may provide an explanation,

\footnotetext{
Supported by the Fondo Nacional de Desarrollo Científico y Tecnológico (FONDECYT-Chile) grants 1100225 and 1140412 (S.L.V.), Comisión Nacional de Investigación Científica y Tecnológica (CONICYT) under ERANet LAC grant ELAC2014/HID-0254 (S.L.V.), FONDECYT-Chile Postdoctoral Fellow grant 3140391 (D.A.R.), and the Chilean Doctoral Scholarship Fund (P.A.I., F.J.P., and A.M.).

Disclosures: None declared.

Presented in part at the 13th International Congress on Pediatric Pulmonology, Bruges, Belgium, June 27, 2014; at the 13th International Workshop on Opportunistic Protists, Sevilla, Spain, November 13 to 15, 2014; and at the 19th Congress of the International Society for Human and Animal Mycology, Melbourne, VIC, Australia, May 4 to 8, 2015.
} 
not currently available, of why the number of infants hospitalized for respiratory infections reaches a peak between the ages of 2 and 5 months. ${ }^{6,7}$ This age risk window is attributed to weaning of maternal antibodies that clearly explain the increasing number of infections. However, factors underlying the high variability in the severity of their clinical presentation are not understood and are generally assumed to be explained by variations in genetic background.

Subclinical primary infection with the nonmicrobiologically cultivable fungus Pneumocystis is likely the most common pulmonary infection in infants aged 2 to 5 months. ${ }^{8-11}$ The high prevalence at this age may be explained by early acquisition of Pneumocystis from the mother, and this risk of acquisition affects similarly immunocompetent and immunocompromised infants. $^{9-17}$

Mothers are likely to carry Pneumocystis because of pregnancy-related physiological immunosuppression, ${ }^{18}$ and they may, therefore, act as an infective reservoir for their own newborns, which may explain the peak incidence of this infection at 2 to 5 months of age. ${ }^{19-21}$ Pneumocystis primary infection has been shown in rodents to be subsequently eliminated from the lungs without resulting in latency. ${ }^{22-24}$ Mild pulmonary infections in immunocompetent adults suggest secondary infections may occur beyond infancy. ${ }^{25}$ Pneumocystis primary infection is typically mild, does not exhibit a characteristic clinical pattern, may be asymptomatic, and goes undiagnosed unless specifically tested..$^{10}$ Nevertheless, Pneumocystis is sometimes associated with upper respiratory tract infection $^{12}$ and occasionally progresses to pneumonitis or apnea. $^{26-28}$ In recent studies of autopsied infant lungs, increased mucus production suggested that this infection has pathologic effects on the immunocompetent infant lung. ${ }^{11,29}$ Furthermore, there is increasing evidence of Pneumocystisrelated immunopathology in immunocompetent murine models. ${ }^{2,30-34}$ Coinfection with a virus and Pneumocystis resulted in fatal exacerbation of Pneumocystis pneumonia (PCP) in immunocompromised mice. ${ }^{35}$ Moreover, intratracheal inoculation of Pneumocystis in immunocompetent mice exacerbates the airway's responses to external insults ${ }^{2,32}$ and induces transient hypoxemia. ${ }^{34}$ In addition, an increase in $\mathrm{CD}^{+}{ }^{+} \mathrm{T}$ cells related to immunoreconstitution in HIV-infected patients has been linked as a factor precipitating airway hyperresponsiveness, ${ }^{36}$ and Pneumocystis was reported to induce $\mathrm{CD} 4^{+}$T-cell-dependent asthma-like disorders. ${ }^{37}$

Although histologic lung lesions are clearly discernible in rats and mice, obtaining lung biopsy specimens from apparently healthy infants to evaluate this subclinical infection histologically is not possible because infants lack an obvious health threat. ${ }^{28} \mathrm{An}$ additional difficulty is posed by the larger size of the infant lung, which may hinder lesion detection because the infection might be focally distributed. Findings in rodent models of Pneumocystis are highly reproducible and generally applicable to a clinical situation. ${ }^{38}$ A rodent model of naturally acquired Pneumocystis infection was, therefore, developed to mimic its acquisition in humans, ${ }^{24}$ and serial examinations of the lungs were performed to assess Pneumocystis growth and evaluate the responses of selected cytokines and chemokines. The histologic damage of the lungs was sequentially monitored using microscopy morphometry of the airways, of vascular-perfused lungs fixed in situ to evaluate selected features of airway disease, including airway epithelial thickening, mucus production, peribronchiolar and perivascular inflammatory cuffs, and remodeling fibrosis. Changes in these parameters establish lung disease and may have deleterious effects on lung function.

The asymptomatic nature of primary Pneumocystis infection and the lack of a culture-based microbiology diagnostic system make clinical diagnosis difficult. Furthermore, the extensive distribution of Pneumocystis infection in infants means there are few uninfected controls, which hampers research investigating this disease in nonimmunosuppressed infant hosts. Therefore, confirming that the naturally acquired primary Pneumocystis infection causes immunopathology with airway remodeling in immunocompetent hosts, as shown herein, would encourage future research aimed at understanding the pathogenic significance of this underlying coinfection.

Overall, our findings confirm that Pneumocystis damages the competent host lung and support the need to evaluate the association between Pneumocystis and respiratory morbidity in the post-neonatal period and beyond. It may be possible to prevent Pneumocystis infection using anti-Pneumocystis chemotherapy or by a vaccine in development, which would facilitate a proof-of-concept study focusing on curtailing Pneumocystis primary infection. ${ }^{38-40}$

\section{Materials and Methods}

\section{Study Design}

The objective of this study was to characterize the pathophysiologic effects of primary Pneumocystis infection in rodent lungs. To achieve this, the progressive pathologic changes in the airway, the induction of innate immunity and fibrosis-related pathways, and the involvement of type 1 helper T-cell and type 2 helper T-cell (Th2) cytokines associated with airway mucus production and fibrosis were measured. The institutional Animal Welfare Ethics Committee of the University of Chile School of Medicine (Santiago, Chile) approved the protocol and animal procedures (number CBA 0634 FMUCH; September 30, 2013). Studies were conducted in accordance with the Animal Protection Law of Chile (Law 20.380) and the Guide for the Care and Use of Laboratory Animals. ${ }^{41}$ Rats were randomized to the experimental groups using randomization tables. The sample size for each study end point was selected empirically without statistical methods. The rats were sacrificed at specific times, which were selected on the basis of the results of pilot experiments, suggesting a peak of Pneumocystis carinii infection at 


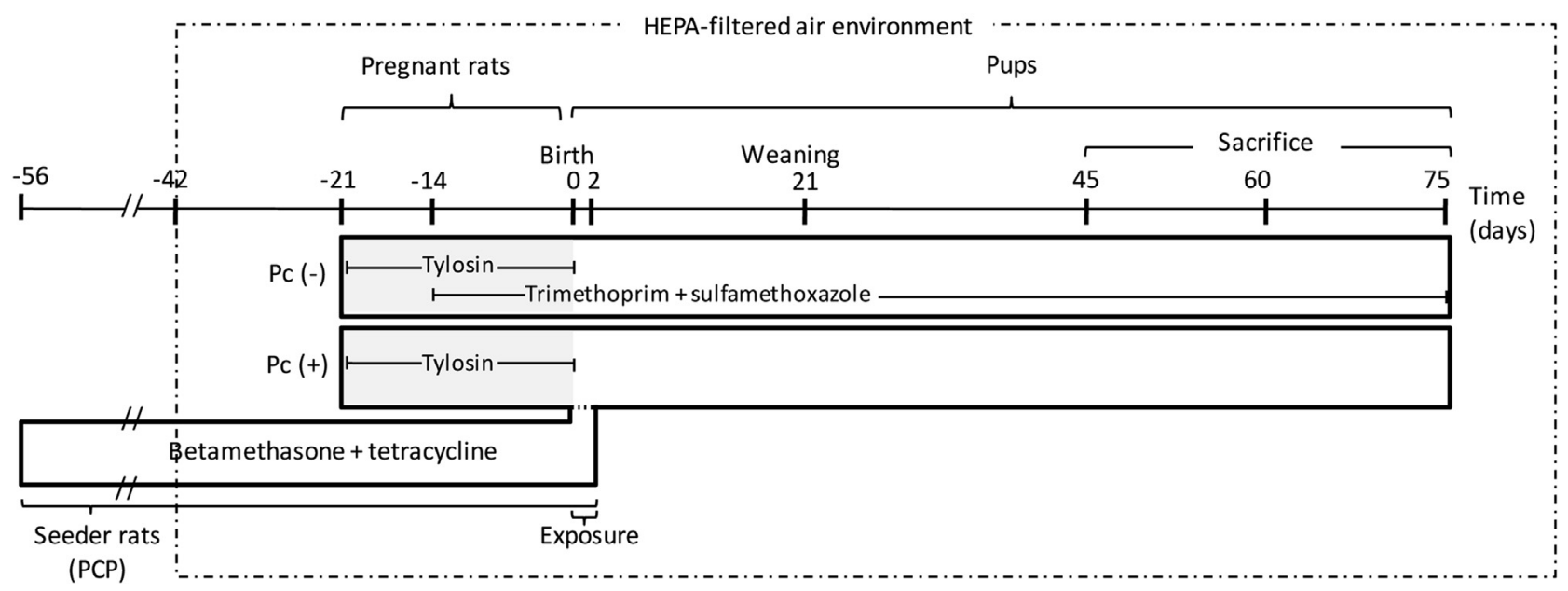

Figure 1 Study design. Thirty-two female Sprague-Dawley rats derived from a single colony were divided into two groups. The first group of 16 rats was treated with betamethasone plus tetracycline for 8 weeks to facilitate the development of Pneumocystis pneumonia (PCP) and used as Pneumocystis seeder rats. The other 16 rats were time mated and received tylosin throughout pregnancy to prevent bacterial infections. Starting on day -21 , eight of the dams were provided with drinking water containing trimethoprim-sulfamethoxazole to prevent Pneumocystis infection until euthanasia (unexposed control group); the other eight dams were given normal drinking water (Pneumocystis-infected group) and exposed to seeder rats with PCP for 48 hours to secure Pneumocystis contagion. Ten pups per group were sacrificed by anesthesia with ketamine plus xylazine on each of days 45,60 , and 75 of age. At each time point, five pups in each group underwent vascular perfusion with buffered formalin in situ to preserve their lung structure for histologic and morphologic analysis. The lungs from the other five pups were dissected for use in molecular analyses. HEPA, high-efficiency particulate air; $\mathrm{Pc}(-)$, uninfected control group; $\mathrm{Pc}(+)$, Pneumocystisinfected group.

approximately day 60 using this cohabitation model. When the rats were sacrificed, the rats in each group were empirically allocated to be used for lung dissection after exsanguination for molecular studies or for vascular perfusion for morphometry assessments.

\section{Animal Model}

Thirty-two female Sprague-Dawley rats (body weight, approximately $250 \mathrm{~g}$ ) whose mothers were derived from a single colony were obtained from the Animal Research Facility, University of Chile School of Medicine. They were housed under controlled light and temperature conditions and received purified water and UV-irradiated food ad libitum throughout the study. The rats were randomly allocated to two groups of 16 rats each (seeder rats and dams), and the dams were then randomized into two groups of eight rats each (exposed dams and control dams), as follows.

\section{Pneumocystis Seeder Rats}

PCP was induced in 16 female rats. Starting on day -56 , the rats were given water containing $3 \mathrm{mg} / \mathrm{L}$ betamethasone and $500 \mathrm{mg} / \mathrm{L}$ tetracycline for immunosuppression. For 2 weeks, they were housed in a normal room to acquire Pneumocystis and were then moved to cages fitted with a high-efficiency particulate air filter (LabProducts Inc., Seaford, DE). Immunosuppression was continued for 6 weeks until the rats were used as seeder rats on days 0 to 2 (Figure 1). All seeder rats were sacrificed after use, and the lungs were confirmed to be positive for Pneumocystis by microscopy using the Grocott-Gomori methenamine silver stain.

\section{Primary Infection Rats and Controls}

Sixteen timed-pregnant dams were housed in high-efficiency particulate air-filtered cages on day -21 and received drinking water containing $66 \mathrm{mg} / \mathrm{L}$ tylosin to prevent bacterial infections. This was continued until delivery. On day -14 , eight control dams were given drinking water containing 2.4 $\mathrm{mg} / \mathrm{mL}$ of trimethoprim and $0.48 \mathrm{mg} / \mathrm{mL}$ sulfamethoxazole to prevent Pneumocystis. This was continued until delivery. The pups of the other eight dams were exposed to Pneumocystis at birth by placing a seeder rat with PCP in a wire box inside the cage for 48 hours. This mode of infection mimics the route and intensity of natural infection. ${ }^{24}$ Ten pups per group were sacrificed on days 45, 60, and 75 of age under deep anesthesia with ketamine $(150 \mathrm{mg} / \mathrm{kg})$ and xylazine $(30 \mathrm{mg} / \mathrm{kg})$. Five were exsanguinated after bronchoalveolar lavage (BAL) with $5 \mathrm{~mL}$ of sterile phosphate-buffered saline, and their lungs were removed and placed in RNA-later (Qiagen, Valencia, CA) for 24 hours at room temperature and then stored at $-80^{\circ} \mathrm{C}$ until they were used for molecular analyses. The other five pups were perfused with $3.7 \%$ buffered formalin $(\mathrm{pH} 7.4)$ at a pressure of $25 \mathrm{~cm} \mathrm{H}_{2} \mathrm{O}$ via the inferior vena cava for 6 minutes, and left at $4{ }^{\circ} \mathrm{C}$ for 24 hours, after which the lungs were removed and placed in buffered formalin for 24 hours. The left lungs were embedded in paraffin and cut into longitudinally oriented sections ( $5 \mu \mathrm{m}$ thick) for microscopy and morphologic analyses. This in situ lung fixation method was used to preserve lung volume after confirming that the lung volume decreases by $60 \%$ of the original lung volume after transpulmonary pressure release caused by opening the thorax. These prior experiments used sibling rats of the same age and weight. They were deeply anesthetized and randomized to sacrifice by 
Table 1 Probe and Primer Sequences

\begin{tabular}{|c|c|c|}
\hline Probe/target & Sequence & Reference \\
\hline \multicolumn{3}{|c|}{ To confirm Pneumocystis carinii infection } \\
\hline pAZ102E & $5^{\prime}$-GATGGCTGTTTCCAAGCCCA-3' & 23 \\
\hline pAZ102H & $5^{\prime}$-GTGTACGTTGCAAAGTACTC-3' & 23 \\
\hline pAZ102X & $5^{\prime}$-GTGAAATACAAATCGGACTAGG-3' & 23 \\
\hline pAZ102L1R & 5'-СTCTCGACTCCTCACСTTAT-3' & 23 \\
\hline \multicolumn{3}{|c|}{ To quantify the burden of Pneumocystis carinii } \\
\hline DHFR11 & 5'-GTTGCACTTACAACTTCTTATGG-3' & 42,43 \\
\hline DHFR12 & $5^{\prime}-$ TAGATCCAGAGATTCATTTCGAG-3' & 42,43 \\
\hline DHFR13 & 5'-CCTCTTTTGTACCAACTTTTGATTCATT-fluorescein-3' & 42,43 \\
\hline DHFR14 & $5^{\prime}$ d-CAL red Fluor 635-GAATCGATGAATGTTGTATTGATGGG-phosphate-3' & 42,43 \\
\hline \multicolumn{3}{|c|}{ To evaluate the host's responses } \\
\hline \multirow[t]{2}{*}{$\operatorname{Tnf}$} & F: $5^{\prime}$-CACCGGCAAGGATTCCAA-3' & * \\
\hline & R: 5'-CACTCAGGCATCGACATTCG-3' & * \\
\hline \multirow[t]{2}{*}{ Il6 } & F: 5'-CССААСТTССААТGСТСТССТААТG-3' & * \\
\hline & R: 5'-GCACACTAGGTTTGCCGAGTAGACC-3' & * \\
\hline \multirow[t]{2}{*}{ Cxcl2 } & F: 5'-AACCATCAGGGTACAGGGGT-3' & * \\
\hline & R: 5'-GGGCTTCAGGGTTGAGACAA-3' & * \\
\hline \multirow[t]{2}{*}{ Tgfb1 } & F: 5'-GACCGCAACAACGCAATCTA-3' & * \\
\hline & R: 5'-TTCCGTCTCCTTGGTTCAGC-3' & * \\
\hline \multirow[t]{2}{*}{ Il10 } & F: 5'-GGCTCAGCACTGCTATGTTGCC-3' & * \\
\hline & R: 5'-AGCATGTGGGTCTGGCTGACTG-3' & * \\
\hline \multirow[t]{2}{*}{ Gata3 } & F: 5'-CCATTACCACCTATCCGCCCTA-3' & * \\
\hline & R: 5'-GTAGAGGTTGCCCCGCAGTT-3' & * \\
\hline \multirow[t]{2}{*}{ Tbet } & F: 5'-CAGCCGTTTCTACCCTGACCTT-3' & * \\
\hline & R: 5'-GAGCAGAGGGTAGGAATGTGGG-3' & * \\
\hline \multirow[t]{2}{*}{ Muc5ac } & F: 5'-ACCACGGATATCAGAACCAGC-3' & * \\
\hline & R: 5'-TGTCAAGCCACTTGGTCCAG-3' & * \\
\hline
\end{tabular}

*Designed for this study.

F, forward; R, reverse.

exsanguination, with their lungs removed immediately, or to in situ lung fixation via cava vein using Bouin fixative, with removal of their lungs after 3 or 6 hours from death. Lung volumes were measured using liquid displacement. Lungs removed after 3 or 6 hours from death doubled the size of unfixed lungs removed immediately, as follows: in situ fixed 6 hours, 100\%; in situ fixed 3 hours, 77.7\%; unfixed and removed immediately, $39.9 \%$. Each percentage volume of lungs with respect to the volume of lungs fixed in situ for 6 hours is the average of three determinations (three rats).

\section{Detection and Quantification of Pneumocystis by Nested PCR and Real-Time Quantitative PCR}

Total genomic DNA was isolated from $0.3 \mathrm{~g}$ aliquots of fresh-frozen homogenized lung tissue using a QIAmp DNA mini kit (Qiagen). Pneumocystis carinii was identified by nested PCR using the oligonucleotides pAZ102-E and pAZ102H, which target the gene encoding mitochondrial large subunit rRNA of Pneumocystis and the internal primers pAZ102X and pAZ102L1R, which are specific for $P$. carinii, as previously described (Table 1 ). ${ }^{23}$ Rat actin was included as an internal control for each specimen. The real-time quantitative PCR assay was performed using the primers DHFR11 and DHFR12, which generate a 234-bp fragment of the single-copy $d h f r$ gene, as previously described (Table 1). ${ }^{42,43}$ All real-time quantitative PCRs were performed in glass capillaries in a final reaction volume of $20 \mu \mathrm{L}$ of LightCycler FastStart DNA Master HybProbe reaction mixture (Roche, West Sussex, UK) containing Fast Start Taq, deoxynucleoside triphosphate, $3 \mathrm{mmol} / \mathrm{L} \mathrm{MgCl}_{2}, 0.5 \mu \mathrm{mol} / \mathrm{L}$ of each primer, $0.2 \mu \mathrm{mol} / \mathrm{L}$ of each fluorescence resonance energy transfer probe, $1 \mathrm{U}$ of heat-labile uracil-DNA glycosilase to prevent carryover contamination, and $2 \mu \mathrm{L}$ of extracted DNA. The fluorescence resonance energy transfer probes were DHFR13 and DHFR14. ${ }^{43}$ A standard curve was generated by amplifying $1 \times 10^{7}$ to $1 \times 10^{10}$ copies of a cloned $P$. carinii dhfr template per PCR. Samples were run in triplicate, and control reactions lacking the template were included in each run.

\section{Histology and Morphometry Assessments}

Histologic and morphometry assessments were performed using an Olympus BX60 microscope connected to a Q-IMAGING Micropublisher 3.3 RTV camera (QImaging, Burnaby, BC, Canada) and analyzed using Image Pro Plus software version 5.1.0 (Media Cybernetics Inc., Rockville, MD). Longitudinal tissue sections ( $5 \mu \mathrm{m}$ thick) were used for all measurements. Measurements were conducted by two 
A

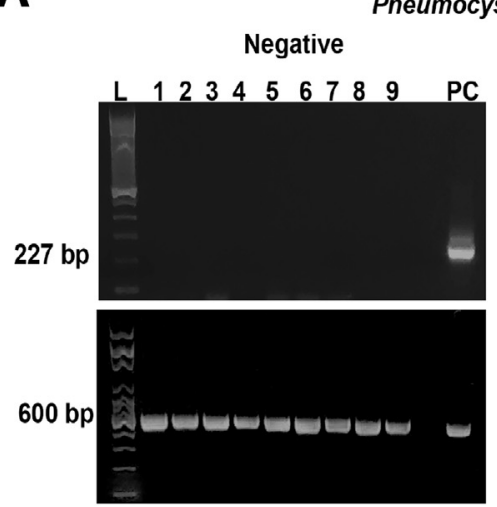

Positive

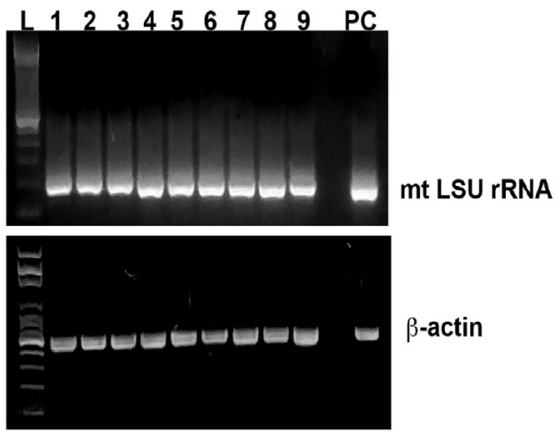

B

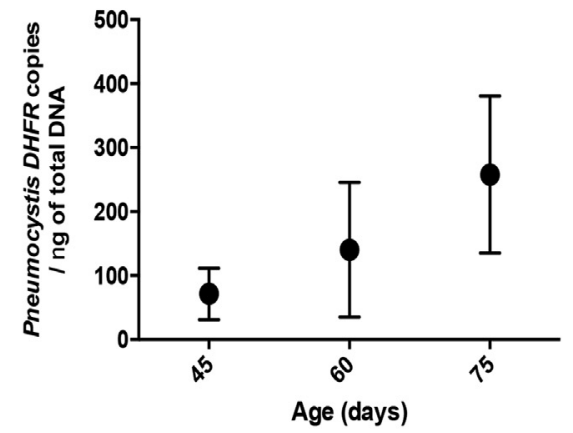

Figure 2 Confirmation of Pneumocystis infection. Pneumocystis carinii infection was assessed in the lungs of experimental rats by nested PCR and quantitative PCR of the gene dhfr. A: Unexposed rats given anti-Pneumocystis prophylaxis [control rats; lanes 1 to 9 in the gel (left panels)] do not develop primary Pneumocystis infection, whereas rats exposed to seeder rats are all positive for $P$. carinii DNA [lanes 1 to 9 in the gel (right panels)]. B: The Pneumocystis burden increases between days 45 and 75 in rats with primary Pneumocystis infection. The progression of Pneumocystis burden was assessed by one-way analysis of variance $(P=0.403)$. Data are expressed as means \pm SD. L, ladder; $\mathrm{mt}$ LSU, mitochondrial large subunit; PC, positive control.

independent observers (P.A.I. and R.B.) who were unaware of the Pneumocystis status of the specimens.

\section{Evaluation of Peribronchiolar and Perivascular Cuffs and Cellular Composition}

The proportions of bronchioles of $<250 \mu \mathrm{m}$ diameter and blood vessels of $<250 \mu \mathrm{m}$ diameter that were surrounded by cellular cuffs were determined on hematoxylin and eosin (H\&E)-stained slides using a modified semiquantitative scoring system ${ }^{44}$ : 0 indicates no surrounding cuffs seen; 1 , cuffs in $<25 \%$ of bronchioles or vessels; 2 , cuffs in $25 \%$ to $50 \%$ of bronchioles or vessels; and 3, cuffs in $>50 \%$ of bronchioles or vessels. A minimum of five bronchioles and five blood vessels were assessed per rat at a magnification of $\times 4$ in all five rats per group/time point. The cellular composition of the cuffs was assessed by measuring the area of increased cellularity in H\&E-stained sections and immunohistochemistry of adjacent deparaffinized sections ( $3 \mu \mathrm{m}$ thick) to count the cells inside the demarcated mirrored areas (oil immersion lens at $100 \times$ ). Sections were stained with the following antibodies in accordance with the manufacturers' instructions after heat antigen retrieval. To detect $\mathrm{CD} 4^{+} \mathrm{T}$ lymphocytes, $\mathrm{CD} 8^{+}$ T lymphocytes, and B lymphocytes, sections were stained with anti-CD4 ${ }^{+}$(biotin-ab111815), anti-CD8 ${ }^{+}$(ab33786), and anti$\mathrm{CD} 22^{+}$(ab65852), respectively (all from Abcam, Cambridge, UK). Mast cells were stained with toluidine blue stain, and eosinophils were stained with modified $\mathrm{H} \& \mathrm{E} .{ }^{45}$ The results are expressed in terms of the cell density (cells $/ \mu \mathrm{m}^{2}$ ).

\section{Thickness of the Bronchiolar Epithelium}

The area $\left(\mu \mathrm{m}^{2}\right)$ of the airway epithelium between the luminal surface and basal membrane, normalized by the perimeter of the basal membrane $(\mu \mathrm{m}$; thickness in $\mu \mathrm{m}=$ area in $\mu \mathrm{m}^{2} /$ perimeter in $\mu \mathrm{m}$ ), was measured using Image Pro Plus software in H\&E-stained slides of at least five bronchioles per rat in at least four rats per group (samples were not available in some rats) to calculate the means $\pm \mathrm{SD}$ of at least 20 observations per group. Bronchiole diameters were $<250 \mu \mathrm{m}$, with a ratio of larger diameter/smaller diameter of $<2$. Normalization by the perimeter permitted the estimation of thickness $(\mu \mathrm{m})$ and intergroup comparisons. Each measurement was normalized individually, and the mean of results was calculated for each group.

\section{Mucus Production}

The relative area of the bronchiolar epithelium occupied by intraepithelial airway mucus was determined in a minimum of five bronchioles per rat in sections $(5 \mu \mathrm{m}$ thick) stained with Alcian blue-periodic acid Schiff ( $\mathrm{pH}$ 2.5). In addition, immunohistochemical staining of mucin 5AC (Muc5ac) was performed using anti-MUC5AC antibody (ab80953) to visualize and quantify the extent of Muc5ac as a representative mucus marker of the mucus stained with Alcian blue.

\section{Quantification of the Peribronchiolar and Perivascular Matrix}

Peribronchiolar and perivascular collagen deposition was measured using Picrosirius red, as previously described. ${ }^{46}$ Briefly, images of at least five bronchioles and five vessels (bronchioles and vessels of $<250 \mu \mathrm{m}$ diameter) were obtained using a polarized light filter (Olympus), and images were converted to monochrome. The mean thickness of the airways and vessels surrounding collagen was calculated as the area of collagen $\left(\mu \mathrm{m}^{2}\right) /$ perimeter $(\mu \mathrm{m})$ of the basal membrane or smooth muscle. Reticulin (type III collagen) was also quantified in at least five bronchioles and vessels per rat using the Gordon and Sweet stain, and the thickness of the reticulin-stained zone surrounding the bronchiole or vessel epithelium was measured in 

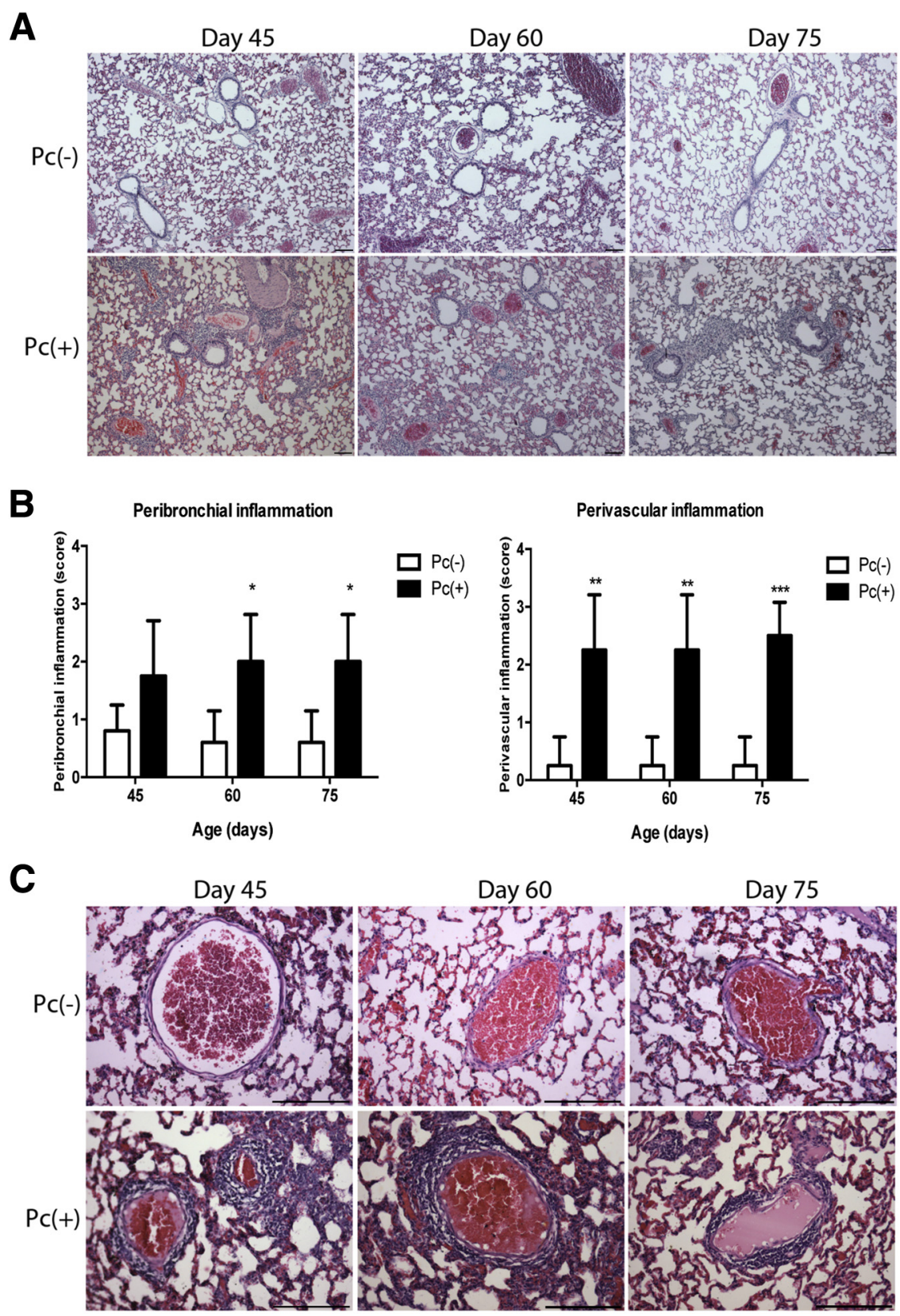

Figure 3 Effects of primary Pneumocystis infection on the numbers of perivascular and peribronchiolar lymphocytic inflammatory cuffs and inflammatory cell infiltration into bronchusassociated lymphoid tissue. A and B: The proportions of bronchioles and vessels surrounded by inflammatory cuffs were assessed by microscopic analysis of hematoxylin and eosin-stained lung sections from uninfected control rats and Pneumocystis-infected rats. The proportions of bronchioles and vessels surrounded by inflammatory cuffs were classified using a score of 0 to 3 (Materials and Methods). The proportion of blood vessels with lymphocytic cuffs is significantly greater in Pneumocystis-infected rats than in control rats on days 45,60 , and 75 . The proportion of bronchioles surrounded by lymphocytic cuffs is also significantly greater in the Pneumocystisinfected rats on days 60 and 75. C: Highermagnification microscopic images of perivascular cuffs show that they are mostly composed of lymphocytic cells. ${ }^{*} P<0.05,{ }^{*} P<0.01$, and $* * * P<0.001$ versus control rats. Scale bars $=100 \mu \mathrm{m}(\mathbf{A}$ and $\mathbf{C})$. Original magnification: $\times 4($ A $) ; \times 20($ C $) . P c(-)$, uninfected control group; $\mathrm{Pc}(+)$, Pneumocystis-infected group. monochrome images. The mean thickness in individual samples was used for intergroup comparisons.

\section{Determination of Immune Response Markers}

Determination of Tnf, Cxcl2, Il6, Il10, Gata3, Muc5ac, Transforming Growth Factor- $\beta 1$, T-bet, and Gata3/T-bet Ratio in Lung Tissue by Quantitative RT-PCR

Total RNA was extracted from fresh-frozen $\left(-80^{\circ} \mathrm{C}\right)$ lung tissues using the Trizol reagent (Invitrogen, Carlsbad, CA), according to the manufacturer's protocol. Nucleic acids were quantified using an Epoch Microplate Spectrophotometer (Biotek, Winooski, VT). RNA $(1 \mu \mathrm{g})$ was used for reverse transcription with random primers and SuperScript
II polymerase (Invitrogen). Amplification of tumor necrosis factor- $\alpha$ (Tnf), macrophage inflammatory protein 2 (Cxcl2), I16, Il10, Gata3, and Muc5ac was performed using the SensiMix SYBR Hi-ROX Kit (Bioline, Taunton, MA) in a RotorGene 6000 Series instrument (Corbett Life Science, Montreal, QC, Canada) and specific primers (Table 1). PCRs consisted of 5 minutes at $94^{\circ} \mathrm{C}$ for initial denaturation, followed by 45 cycles of 30 seconds at $94^{\circ} \mathrm{C}, 20$ seconds at $60^{\circ} \mathrm{C}$, and 20 seconds at $72^{\circ} \mathrm{C}$. Actin was used as the internal control.

Measurement of Il4 and Il13 in BAL Samples

BAL samples were centrifuged at $4^{\circ} \mathrm{C}$ in a refrigerated centrifuge (Fisher Scientific, Waltham, MA), and the 

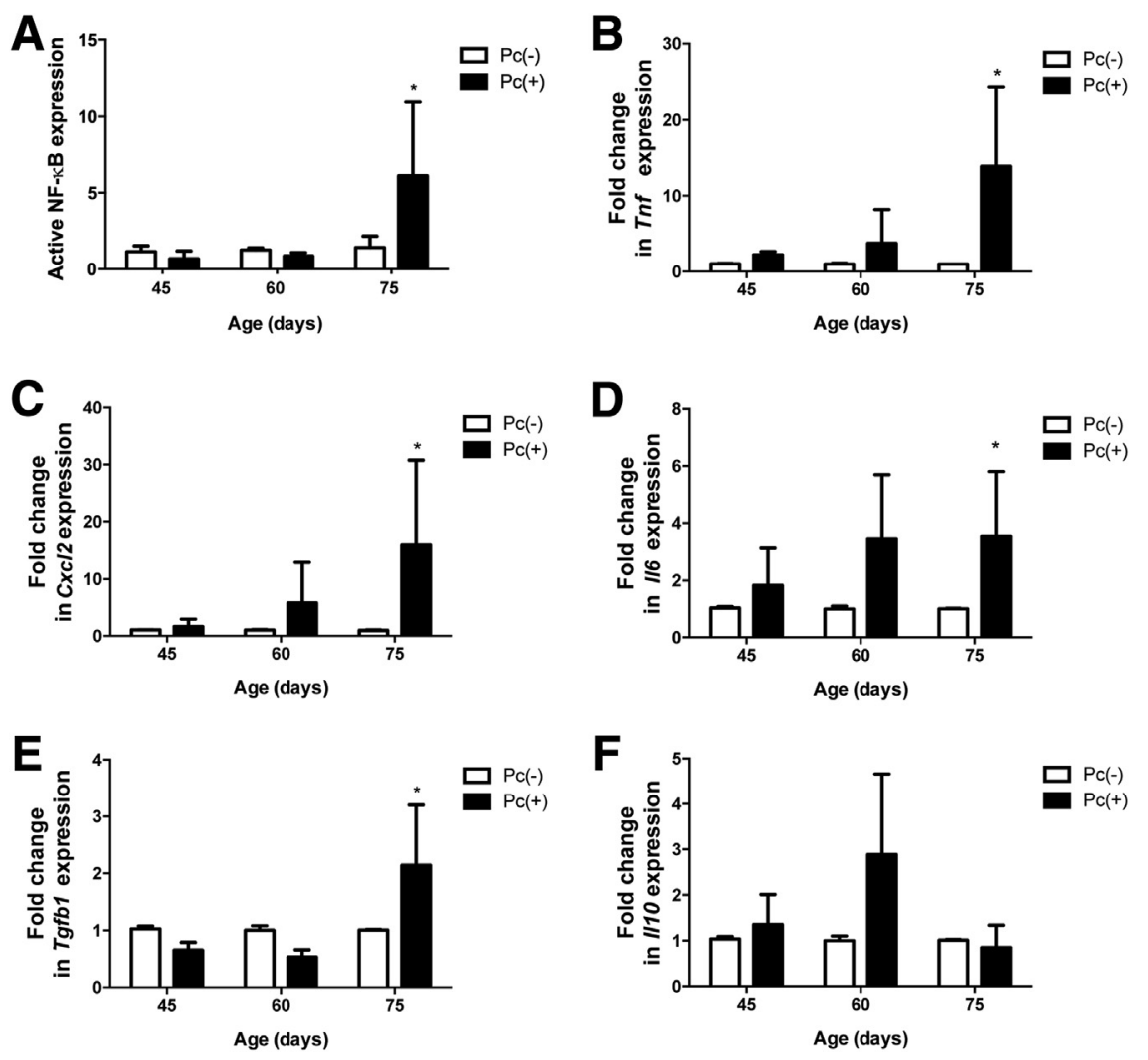

Figure 4 Primary Pneumocystis infection induces an inflammatory response in the lung. A: Activation of the NF- $\kappa B$ signaling pathway in Pneumocystis-exposed rats. Results are presented as arbitrary units for the levels of phosphorylated NF- $\kappa B$ p 65 protein normalized to total $p 65$ and $\beta$ actin. B-F: mRNA expression levels of $\operatorname{Tnf}(\mathbf{B})$, Cxcl2 (C), Il6 (D), Tgfb1 (E), and Il10 (F) in the lung. Results are expressed as the fold-change in gene expression calculated using the $2^{- \text {ddct }}$ method, with the noninfected group used as the baseline. The expression levels of all cytokines, except for Il10, tend to increase on day 60 and increase significantly on day 75 in Pneumocystisinfected rats compared with control rats. The mRNA level of $I l 10$ is not significantly different between the two groups. Data are expressed as means \pm SD. $n \geq 4$ rats per group for all observations. ${ }^{*} P<0.05$ versus the noninfected group at the corresponding time point. $\operatorname{Pc}(-)$, uninfected control group; $\mathrm{Pc}(+)$, Pneumocystis-infected group. concentrations of Il4 and Il13 (in pg/mL) were measured in supernatants using enzyme-linked immunosorbent assay kits (ab100771 and ab100766, respectively; Abcam).

\section{Western Blotting for Muc5ac and NF- $\kappa \mathrm{B}$}

Lung samples $(0.3 \mathrm{~g})$ were disrupted using a Tissue Tearor (Biospec, Bartlesville, OK) in chilled modified radioimmunoprecipitation assay lysis buffer $[\mathrm{pH} 7.4 ; 50 \mathrm{mmol} / \mathrm{L}$ Tris (pH 7.4), $1 \%$ NP-40, $0.5 \%$ sodium deoxycholate, 150 $\mathrm{mmol} / \mathrm{L} \mathrm{NaCl}$, and $1 \mathrm{mmol} / \mathrm{L}$ EDTA] supplemented with protease inhibitor cocktail (Roche, Mannheim, Germany) and SDS (to a final concentration of $0.01 \%$ in each sample). Gastric tissue was used as a control. Total protein was quantified in supernatants using the Bradford assay (Bio-Rad, Hercules, CA). Samples $(30 \mu \mathrm{g})$ were subjected to SDS-PAGE with $4 \%$ stacking and $8 \%$ resolving Tris-glycine gels. Proteins were transferred to polyvinylidene difluoride membranes and blocked with 5\% low-fat milk. Mouse anti-Muc5ac IgG antibody (1:4000; 45M1; Santa Cruz Biotechnology, Dallas, TX) and goat anti-mouse IgG horseradish peroxidase-conjugated antibody (1:4000; Santa Cruz Biotechnology) were used to detect Muc5ac. Rabbit anti-NF-kB p65 (1:1000; D14E12; Cell Signaling Technology, Danvers, MA) and rabbit anti-phosphorylated NF- $\kappa$ B p65 (1:1000; 93H1; Cell Signaling Technology) were used in total extracted protein, to assess NF- $\kappa \mathrm{B}$ activation. Membranes were stripped, blocked, and reprobed using anti-actin antibodies [goat anti-actin IgG (1:2000) and donkey anti-goat IgG horseradish peroxidase
(1:2000); Santa Cruz Biotechnology]. Enhanced chemiluminescence reagent was used for membrane development (Pierce ECL WB Substrate; Pierce Biotechnology, Rockford, IL), and the films were analyzed using ImageJ software version $1.39 \mathrm{O}$ (NIH, Bethesda, MD; http://imagej.nih.gov/ij).

\section{Statistical Analysis}

GraphPad Prism software version 7 (GraphPad Inc., San Diego, CA) was used for all analyses. Results are expressed as means $\pm \mathrm{SD}$ or interquartile ranges, or as described in figure legends. One-way analysis of variance with the Bonferroni test for multiple comparisons was used to compare the pulmonary Pneumocystis load and cell counts among the three time points. Two-way analysis of variance was used to analyze the proportion of bronchioles or vessels with surrounding inflammatory infiltrates and to compare data between Pneumocystis-infected rats and control rats. In all analyses, $P<0.05$ was considered statistically significant.

\section{Results}

Acquisition and Progression of Primary Pneumocystis Infection

Pneumocystis was monitored in a group of rats used for infectivity (seeder rats) and in two experimental groups (Figure 1). All seeder rats developed PCP, which was 


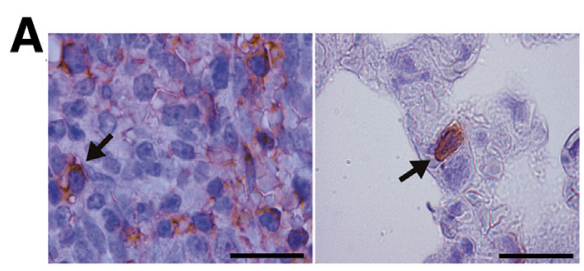

D

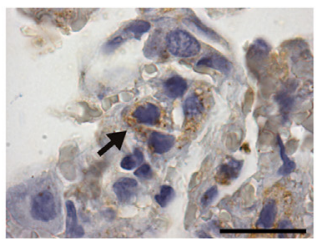

G

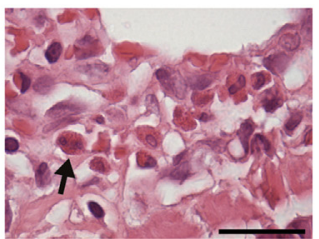

J

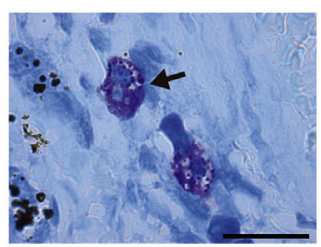

B

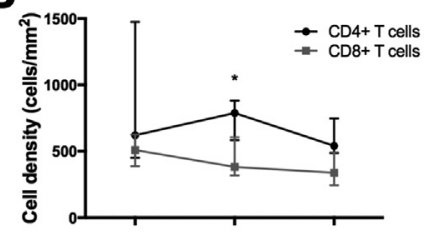

E

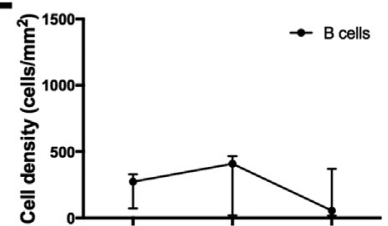

H

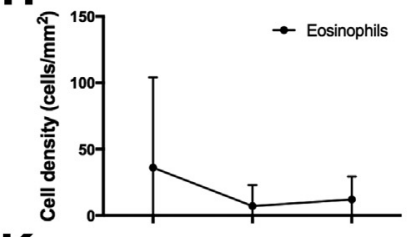

$K$

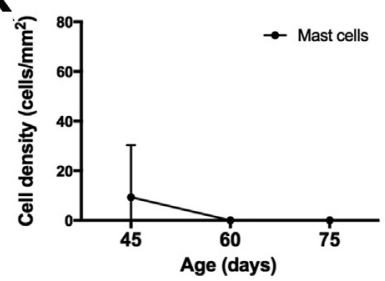

C

F

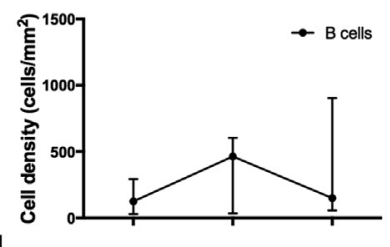

I

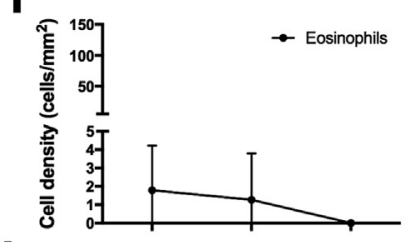

$\mathbf{L}$

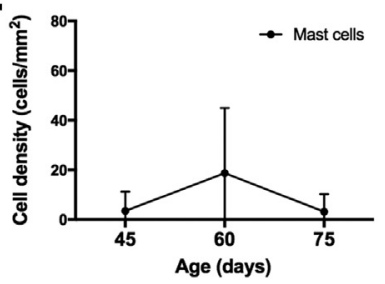

Figure 5 Cellular composition of the peribronchiolar (B, E, H, and $\mathbf{K}$ ) and perivascular (C, F, I, and L) cuffs of Pneumocystis-infected rats. The composition of the cuffing infiltrates was assessed by microscopy and immunohistochemical staining, with specific monoclonal antibodies for CD4 ${ }^{+} \mathrm{T}_{\text {cells }}(\mathbf{A}$, left panel), $\mathrm{CD}^{+} \mathrm{T}$ cells $\left(\mathbf{A}\right.$, right panel), and CD22 ${ }^{+}$B cells (D), a modified hematoxylin and eosin stain for eosinophils (G), and a toluidine blue stain for mast cells (J) in the Pneumocystis-infected rats. Values are presented as the means of five bronchioles $(\mathbf{B}, \mathbf{E}, \mathbf{H}$, and $\mathbf{K})$ or vessels $(\mathbf{C}, \mathbf{F}, \mathbf{I}$, and $\mathbf{L})$ per rat in five rats per group. The error bars represent the interquartile range. The composition of the cuffs was similar around bronchioles $(\mathbf{B}, \mathbf{E}, \mathbf{H}$, and $\mathbf{K})$ and vessels $(\mathbf{C}, \mathbf{F}, \mathbf{I}$, and $\mathbf{L})$. CD4 ${ }^{+}$ cells are more frequent than $\mathrm{CD}^{+} \mathrm{T}$ cells $(\mathbf{B})$ and $\mathrm{B}$ cells $(\mathbf{B}$ and $\mathbf{E})$ in the Pneumocystis-infected rats. The density of $\mathrm{CD} 4^{+} \mathrm{T}$ cells reached a peak at day 60 days. Cells were absent or too low to count in the control group to make statistical comparisons. Arrows point to cell type plotted in their side adjacent graphs. ${ }^{*} P<0.05$ versus $\mathrm{CD}^{+} \mathrm{T}$ cells. Scale bars $=10 \mu \mathrm{m}(\mathbf{A}, \mathbf{D}, \mathbf{G}$, and $\mathbf{J})$.

confirmed by microscopy and Grocott-Gomori methenamine silver staining of lung sample imprints (touch preparations). When the rats were sacrificed, Pneumocystis was assessed by nested PCR using lung tissue samples from Pneumocystis-exposed and unexposed control rats receiving anti-Pneumocystis prophylaxis. The exposed rats were positive for Pneumocystis in all samples tested, whereas the rats in the control groups were negative for Pneumocystis (Figure 2A). The Pneumocystis burden in lung tissues (dhfr gene copies/ng of total DNA) increased further from days 45 to 75 , although the increase in burden was not statistically significant (Figure 2B).

\section{Inflammatory Responses to Primary Pneumocystis Infection}

The overall inflammatory state was next assessed under a microscope at low magnification $(\times 4)$ (Figure 3A). Lung sections were stained with $\mathrm{H} \& \mathrm{E}$ and scored according to the proportion of blood vessels and bronchioles surrounded by inflammatory cells. Cuffing inflammation may lead to extracellular matrix deposition, may thicken the tissue interphase involved in oxygen diffusion, and may impair oxygen uptake, resulting in hypoxia. However, this was not determined in our study. Inflammatory cuffs were observed around capillaries starting on day 45 and around bronchioles on day 60 in exposed rats but not in control rats (Figure 3, A and B). Dense lymphocytic infiltrates corresponding to bronchus-associated lymphoid tissue and sparse interstitial lymphocytes in a cuff-like configuration were intense around vessels (Figure 3C) and only observed in rats exposed to Pneumocystis (Figure 3, A and B).

To relate the histologic findings to inflammatory response markers, NF- $\kappa \mathrm{B}$ activation and the mRNA expression levels of genes expressing the following proinflammatory and anti-inflammatory cytokines were measured: Tnf, Il6, $\mathrm{Cxcl} 2$, transforming growth factor- $\beta 1$, and Il10. NF- $\kappa \mathrm{B}$ activation, which was determined in total extracted protein by measuring phosphorylated $\mathrm{NF}-\kappa \mathrm{B}$ p65 expression relative to total p65 and $\beta$-actin, was greater in 

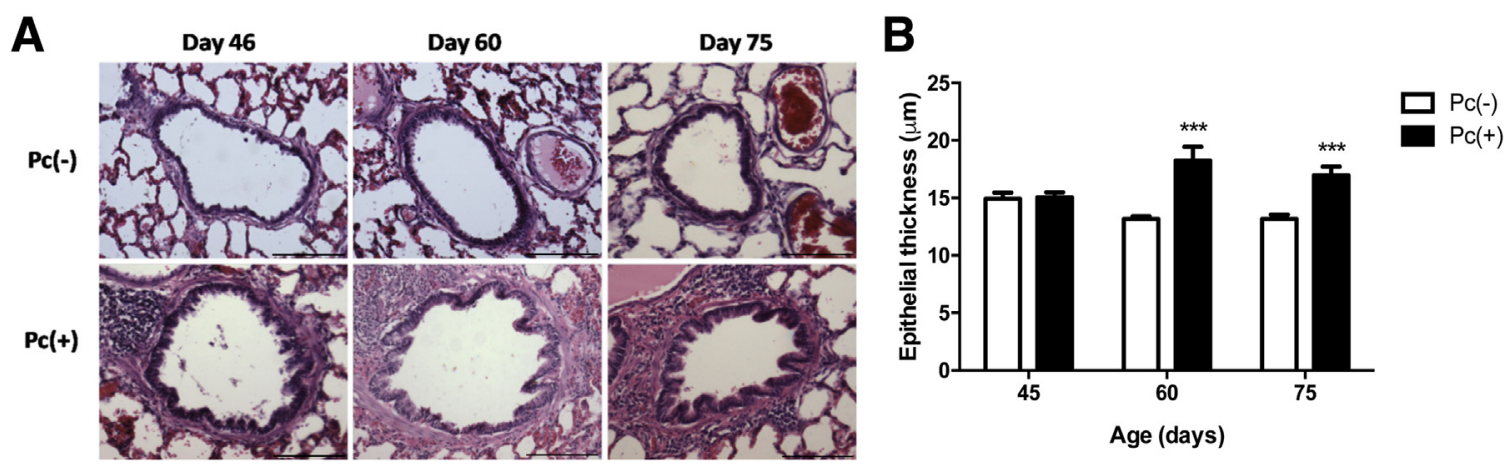

Figure 6 Primary Pneumocystis infection increases the thickness of the airway epithelium. A: Representative images showing epithelial thickening in the Pneumocystis-infected rats. Tissues were stained with hematoxylin and eosin. B: Quantification of epithelial thickness, defined as the area between the basal membrane and the lumen (in $\mu \mathrm{m}^{2}$ ) normalized by the perimeter of the basal membrane $(\mu \mathrm{m})$. The epithelium was approximately one-third thicker in Pneumocystis-infected rats than in control rats on days 60 and 75. Data are expressed as means \pm SD (B). $n=4$ bronchioles per rat in 5 rats per group (B). ${ }^{* * *} P<0.001$ versus control rats. Scale bars $=100 \mu \mathrm{m}(\mathbf{A})$. Original magnification, $\times 10(\mathbf{A})$. $\mathrm{Pc}(-)$, uninfected control group; $\mathrm{Pc}(+), \operatorname{Pneumocystis-infected}$ group.

Pneumocystis-exposed rats than in control rats on day 75 . Similarly, the mRNA levels of Tnf, Il6, and Cxcl2 were elevated from day 60 and increased further on day 75 after infection (Figure 4, A-E). By contrast, the Il10 mRNA level was not significantly different between Pneumocystisexposed rats and control rats (Figure 4F). Cellular infiltrates comprising $\mathrm{T}$ and mature $\mathrm{B}$ lymphocytes were observed from day 45 (Figure 5, A-F), with a significant predominance of $\mathrm{CD}^{+}$cells over $\mathrm{CD}^{+}$cells in the cuffing infiltrates (Figure 5B). B-cell lymphocytes, eosinophils, and mast cells were observed in peribronchial and perivascular cuffs from day 45 (Figure 5, D-L).
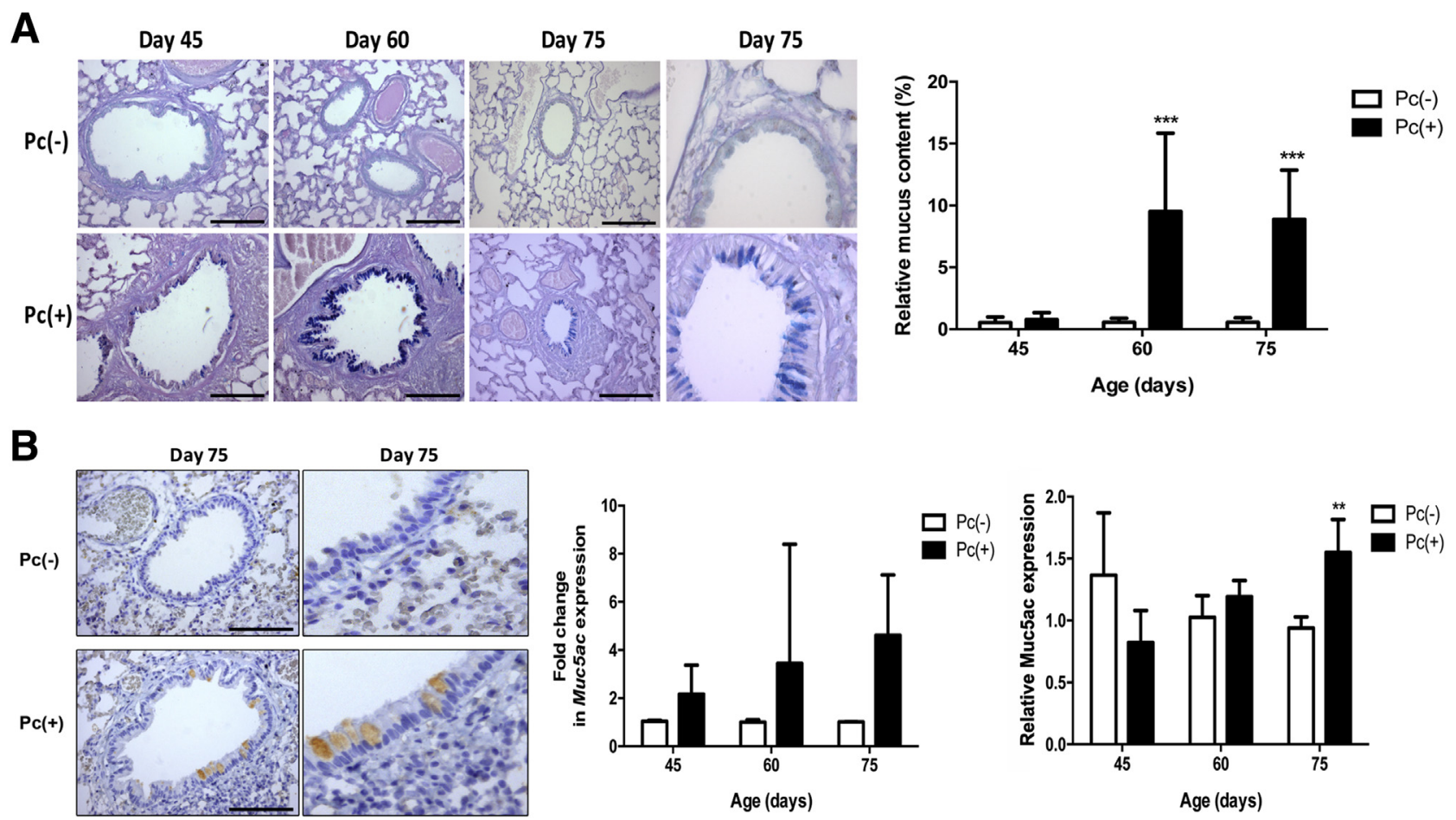

Figure 7 Primary Pneumocystis infection increases mucus production in the airway. A: Representative images showing the progression of mucus within the epithelium. Mucus content was assessed as the percentage area of epithelium between the basal membrane and the luminal surface that was positive for Alcian blue-periodic acid Schiff stain. Mucus content is significantly increased on days 60 and 75 in Pneumocystis-infected rats than in the control group. B: Mucin $5 A C$ (Muc5ac) immunohistochemically stained histology sections. Anti-Muc5ac identifies a fraction of the total histochemically stained mucus. Plots of RT-PCR of Muc5ac, as a marker of mucus, and of Muc5ac Western blotting, show the mRNA expression levels of Muc5ac and the Muc5ac protein increase on day 75 in Pneumocystis-infected rats compared with control rats. mRNA and Muc5ac protein expression were normalized to $\beta$-actin expression. Data are expressed as means \pm SD. $n=5$ bronchioles per rat in four rats per group $(\mathbf{A}) ; n=4$ rats per group $(\mathbf{B}) .{ }^{*} P<0.01,{ }^{* *} P<0.001$ versus control rats. Scale bars $=100$ $\mu \mathrm{m}(\mathbf{A}$ and $\mathbf{B})$. Original magnification: $\times 40$ (A and B, rightmost columns). $\mathrm{Pc}(-)$, uninfected control group; $\mathrm{Pc}(+)$, Pneumocystis-infected group. 

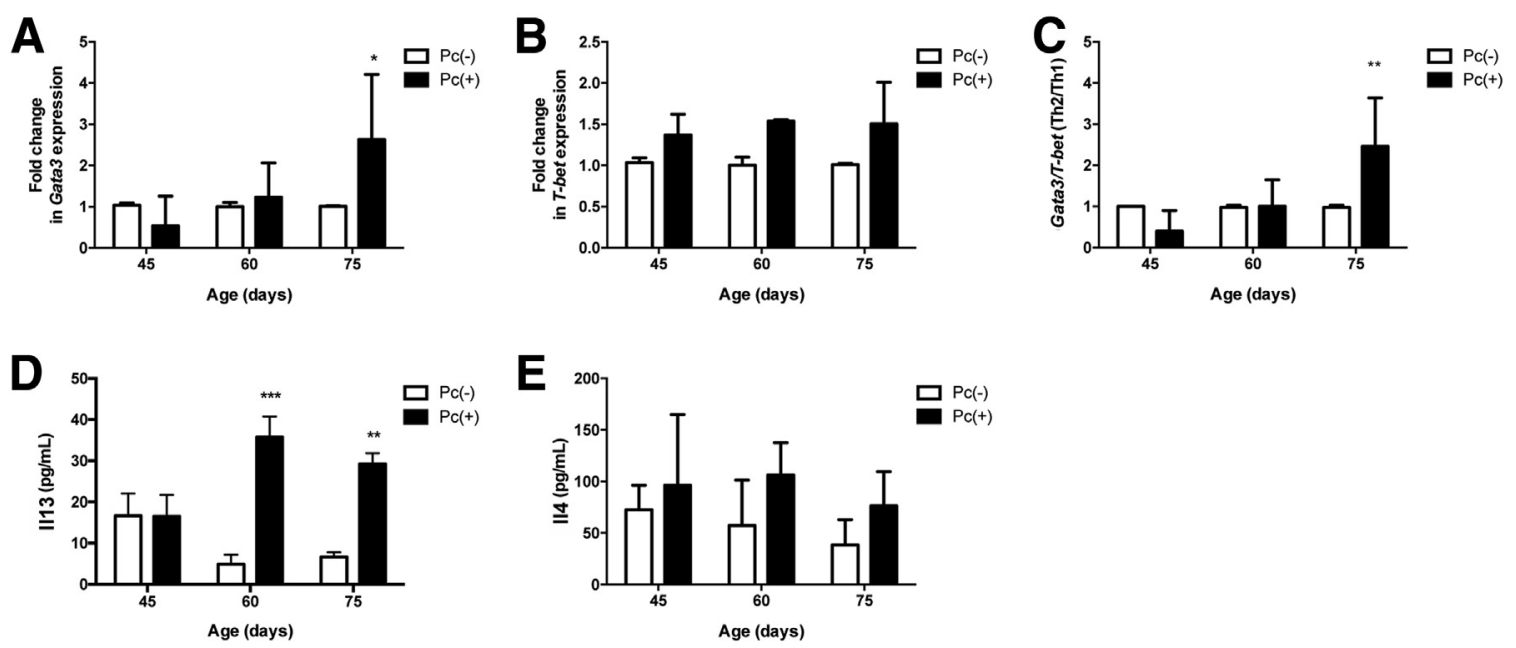

Figure 8 Primary Pneumocystis infection is characterized by a type 2 helper T-cell (Th2) immune response. A-C: Primary Pneumocystis infection is associated with a significant increase in Gata3 $\mathrm{mRNA}$, the main transcription factor involved in $\mathrm{CD}_{4}^{+} \mathrm{T}$-cell transformation (Th2 response), on day 75 (A); with nonsignificant changes in T-bet mRNA, the transcription factor for type 1 helper T cells (Th1s) (B); and with a significant increase in the Gata3/T-bet (Th2/ Th1) ratio (C). D: Il13 levels in bronchoalveolar lavage (BAL) fluid were elevated from day 60 in Pneumocystis-exposed rats, consistent with Th2 activation and activation of the Th2-dependant STAT-6 pathway, which induces mucin secretion. E: Il4 levels in BAL fluid are not significantly different between the two groups. ${ }^{*} P<0.05$, ${ }^{*} P P<0.01$, and ${ }^{*} * P<0.001$ versus control rats. $\mathrm{Pc}(-)$, uninfected control group; $\mathrm{Pc}(+)$, Pneumocystis-infected group.

\section{Airway Epithelial Responses to Primary Pneumocystis Infection}

The thickness (in $\mu \mathrm{m}=$ epithelial area in $\mu \mathrm{m}^{2} /$ perimeter in $\mu \mathrm{m})$ of the epithelium of small conducting airways was next measured because epithelial thickening may not be apparent to the naked eye. Epithelial thickening can impose a significant physiological burden, according to the Poiseuille law, by decreasing airway diameter and increasing breathing labor, which may ultimately compromise respiratory function. The bronchiolar epithelium on days 60 and 75 was significantly thicker in Pneumocystis-infected rats than in control rats (Figure 6).

\section{Airway Mucus Response to Primary Pneumocystis Infection}

The progression of the mucus remodeling response of the airway epithelium was assessed because it may cause acute changes in airway diameter and mucociliary clearance. Increased mucus production was observed in autopsied infant lungs with primary Pneumocystis infection. ${ }^{11,29}$ Lung tissue sections from Pneumocystis-infected rats stained with Alcian blue showed a distinctive change to a mucus hypersecreting phenotype. This response peaked at day 60 after infection and was maintained at day 75 (Figure 7A). To relate these findings in rats to prior observations in infant lungs, immunohistochemistry was performed to detect Muc5ac, a mucus marker. The immunohistochemical findings were consistent with those of Western blotting and RT-PCR for the detection of the Muc5ac protein and mRNA. These changes increased at day 75 after infection (Figure 7B).

\section{Primary Pneumocystis Infection Induces a Th2 Profile}

To relate these findings to an ongoing Th2 immune response, the Gata3/T-bet mRNA level ratio was evaluated using total RNA extracted from lung tissues. Increases in Gata3 mRNA and in the Gata3/T-bet mRNA level ratio were observed in Pneumocystis-exposed rats on day 75 compared with those in control rats (Figure 8, A-C). Measurements in BAL fluid showed that the Th2 cytokine Il13 was up-regulated in Pneumocystis-infected rats, whereas Il4 levels did not differ from those in control animals (Figure 8, D and E).

\section{Primary Pneumocystis Infection Induces Extracellular Matrix Deposition}

Finally, the extent of fibrosis was examined to document whether inflammatory infiltrates on bronchioles and lung vessels, resulting from the primary Pneumocystis infection, might induce chronic airway changes. The thickness of the collagen type I and type III fiber layer surrounding the bronchioles and blood vessels was measured histologically. Vascular and bronchiolar collagen thickness increased starting on day 60 after infection in lung sections stained with Sirius red. Reticular fibers (type III collagen), indicating well-established fibrosis, were elevated at 60 and 75 days in the bronchioles and vessels of Pneumocystis-infected lung sections stained using the Gordon and Sweet method (Figure 9).

\section{Discussion}

This experimental model of primary Pneumocystis infection revealed progressive pathologic changes characteristic of 


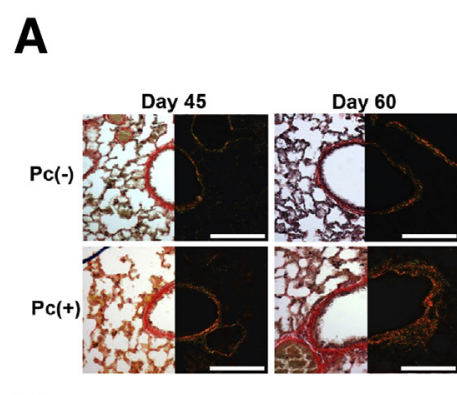

B
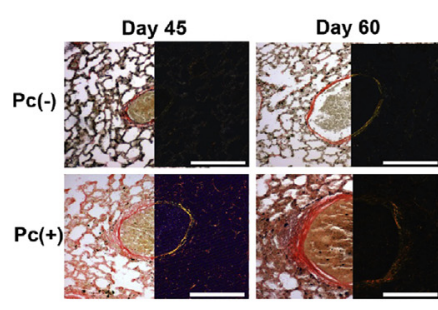

C
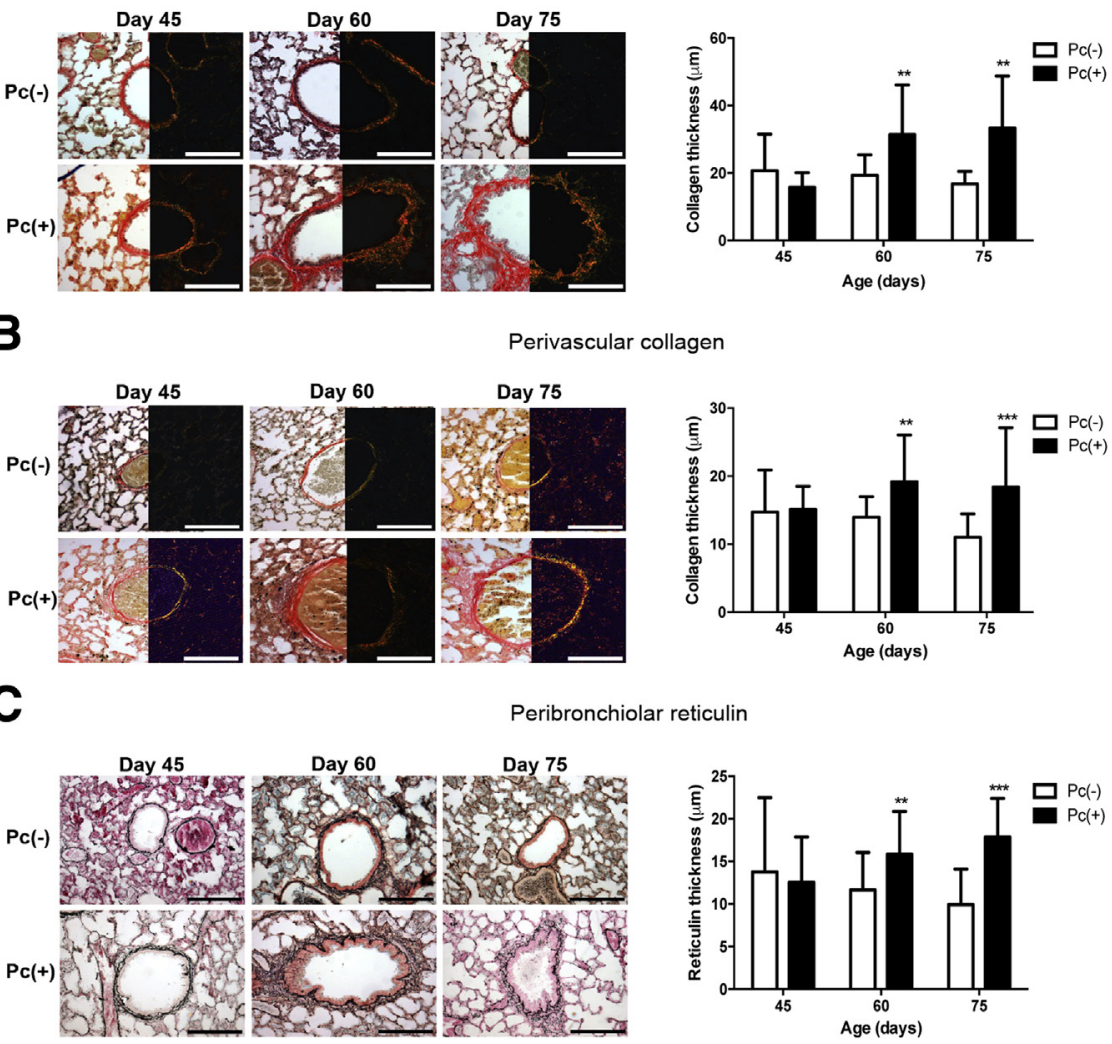

Perivascular collagen

D
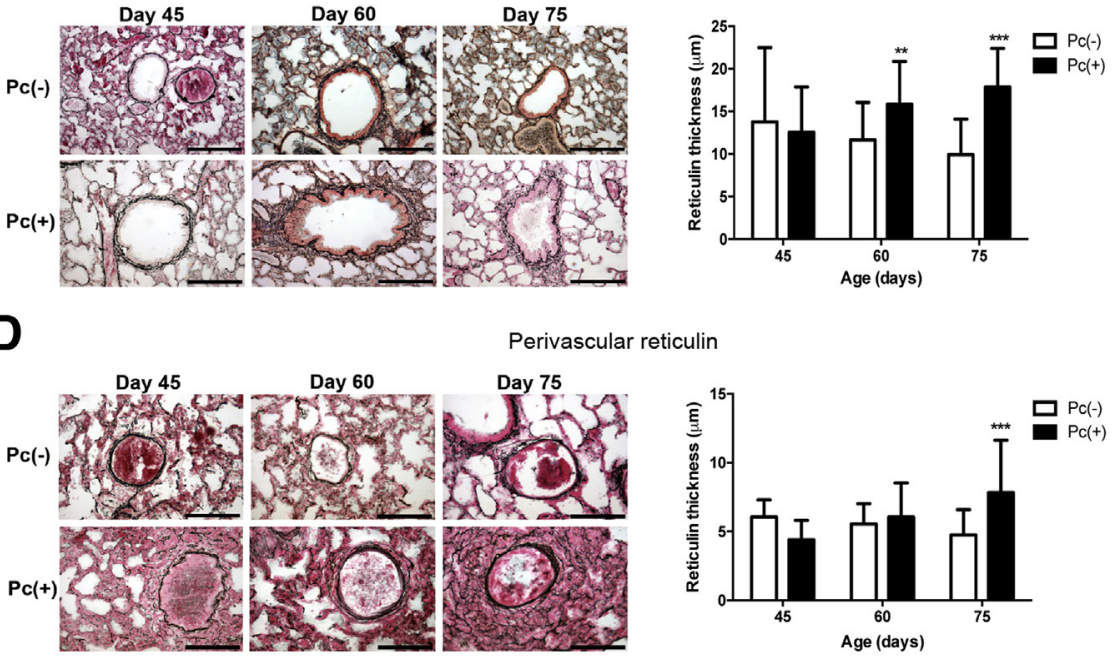

Figure 9 Effects of primary Pneumocystis infection on peribronchiolar and perivascular matrix deposition and fibrosis. Primary Pneumocystis infection increases peribronchiolar (A) and perivascular (B) collagen type I deposition on days 60 and 75 compared with control rats. Primary Pneumocystis infection increases peribronchiolar (C) and perivascular (D) collagen type III (reticulin fibers) deposition on days 60 (peribronchiolar only) and 75 (peribronchiolar and perivascular) compared with control rats. Data expressed as means $\pm S D(A-D) . n=5$ bronchioles or vessels per rat in 4 rats per group $(\mathbf{A}-\mathbf{D}) .{ }^{*} P>0.01$, ${ }^{* * * P}<0.001$ versus control rats. Scale bars $=100 \mu \mathrm{m}(\mathbf{A}-\mathbf{D})$. Original magnification, $\times 10(\mathbf{A}-\mathbf{D}) . \mathrm{Pc}(-)$, uninfected control group; $\mathrm{Pc}(+)$, Pneumocystis-infected group. airway disease that occurred in parallel with changes in markers of the host immune response in an immunocompetent host. The model mimics the natural mode of acquisition and the progression of the primary Pneumocystis infection in the general human population. ${ }^{24}$ Histochemical staining and evaluation of Muc5ac as a mucus marker revealed a progressive increase in mucus production in Pneumocystisinfected mice, consistent with the increase in mucus production attributed to Pneumocystis infection in human infant lungs. ${ }^{18,29}$ The increase in mucus production occurred in parallel with an increase in BAL fluid levels of I113, and together with a downstream increase in the levels of Gata3 mRNA in lung tissue. These findings are consistent with those of prior reports showing that intratracheally inoculated Pneumocystis stimulates mucus production by activating the STAT-6 pathway. ${ }^{33}$ Thickening of the airway epithelium, airway narrowing, and peribronchiolar and perivascular inflammatory cuffs were observed. This histologic damage is consistent with a predominant Th2-type response characterized by increased mucus production, thickening of the airway epithelium, and increased $\mathrm{CD}^{+} \mathrm{T}$ cells in perivascular and peribronchial inflammatory infiltrates. ${ }^{47}$ These findings also confirm that Pneumocystis promotes a $\mathrm{CD}^{+}{ }^{+} \mathrm{T}$-cell-dependent asthmalike pathology in spontaneously acquired primary infection, as reported in animals intratracheally inoculated with the fungus. $2,33,37$

Matrix deposition was also apparent in terms of increased type I and type III collagen deposition, which suggests that Pneumocystis promotes tissue fibrosis. These histologic features were documented up to day 75 of age and occurred in parallel with increased levels of the inflammatory cytokines Tnf, Il6, and $\mathrm{Cxcl} 2$, confirming activation of the $\mathrm{NF}-\kappa \mathrm{B}$ inflammatory pathway, which was previously associated with Pneumocystis. ${ }^{48}$ The increased Il6 levels are suggestive of macrophage activation, ${ }^{49}$ and occurred together with an increase in the level of transforming growth 
factor- $\beta 1$, a regulator of inflammation, and a nonsignificant increase in Il10 levels. The rats appeared healthy despite sequential activation of the histologic features of inflammation. Tissue histology revealed the pathologic state at 45 days after exposure to Pneumocystis, which indicates that slow development of infection precedes noticeable tissue damage, which persisted until day 75 , corresponding to the last time point of the study. Accumulating evidence indicates that primary Pneumocystis infection in normal infants involves a distinct infectious process that is age consistent and differs in terms of its intensity and burden of Pneumocystis organisms to the milder Pneumocystis colonization of immunocompetent adults. Although primary Pneumocystis infection is generally symptomless, it sometimes develops into a self-limiting symptomatic pulmonary infection $^{26,27}$ or into severe PCP in immunocompromised individuals. $^{13}$ Immunosuppressed individuals with non-HIV-related PCP show similarly elevated levels of serum $\beta$-glucan to those of infants with primary infection, suggesting they have a similar lung burden of Pneumocystis. ${ }^{50}$ The infection is difficult to detect in live infants because Pneumocystis does not grow in diagnostic cultures and is easily missed if more virulent cultivable respiratory pathogens or airway insults are identified. However, primary Pneumocystis infection is detectable by trained observers in simple microscopy of tissue samples from autopsied infant lungs. ${ }^{9,28}$ The microscopic diagnostic rate of up to $90 \%$ is possible with direct immunofluorescence of lung homogenates from 3- to 5-month-old infants. ${ }^{11}$ Pneumocystis infection shows a much milder phenotype, with sparsely distributed organisms and a much lower organism burden in nonimmunosuppressed adults, in whom microscopic diagnosis is impractical and extremely laborious and molecular diagnosis requires tissue concentration techniques. ${ }^{25}$

On the basis of the lung damage that occurred in rats in the study, it is possible that primary Pneumocystis infection increases the vulnerability of infants to respiratory insults. There is increasing evidence suggesting that Pneumocystis can sensitize the airway to nonspecific insults. ${ }^{2,47,51}$ Moreover, the increased levels of Il6 and transforming growth factor- $\beta 1$ (a member of the transforming growth factor superfamily of proteins that promotes fibrosis) and the Pneumocystis-associated remodeling fibrosis documented in this model represent consistent evidence to suggest that primary Pneumocystis infection favors acute airway hyperreactivity, with wheezing and chronic airway disease beyond infancy. ${ }^{52,53}$

The infant lung is more vulnerable than the adult lung because of smaller size and the characteristics of the developing respiratory system [narrower airways, the smaller area for gas exchange, lack of interalveolar communications or Cohn pores, increased pulmonary elasticity with a higher respiratory rate (shorter breath cycle) and less time for oxygenation, and fetal-to-adult hemoglobin switching]. In addition, the orientation of the diaphragm and the flexible thoracic cage in infants may hinder the lung's ability to reexpand in acute events, such as airway collapse.
Therefore, it is essential to study whether the pathologic features observed in rats can affect lung function in infants. This is especially important because of the consistently high prevalence of Pneumocystis infection detected in autopsied lungs of 2- to 5-month-old infants, which coincides with a period of age of increased respiratory morbidity and mortality in infants in the general population. Infant age is in itself a highly relevant risk factor for increased severity of Pneumocystis infection, considering the disproportionately higher mortality of infants $(60 \%)$ versus adults $(10 \%)$ within the same context of AIDS-related PCP. ${ }^{54}$ Mild Pneumocystis infections in certain adult populations can lead to chronic diseases, as shown in patients with chronic obstructive pulmonary disease, in whom Pneumocystis colonization is associated with greater severity of chronic obstructive pulmonary disease. Mild Pneumocystis colonization induces chronic obstructive pulmonary disease progression and increases bronchial-associated lymphoid tissue in nonhuman primate models of AIDS-related immunosuppression. ${ }^{55,56}$ These changes do not revert with anti-Pneumocystis therapy, ${ }^{57}$ suggesting prophylaxis as a necessary strategy to avoid damage.

Reports describe pathologic lesions, consistent with the findings, in autopsied infant lungs ${ }^{28}$ and the examination of archived autopsied lungs of infants who died suddenly in the community revealed mild histologic features. ${ }^{15}$ Agematched case-control studies in infants to document a causality relationship are not feasible. However, some of the pathologic findings documented in this work are consistent with previous reports of pulmonary lesions in immunocompetent rats, ${ }^{30,31}$ and with activated immune responses documented in other murine models. ${ }^{2,32-34}$ For example, inflammatory infiltrates that were consistent with interstitial pneumonia of an unknown etiology and were accompanied by prominent perivascular infiltrates were observed in previously healthy immunocompetent rats 7 weeks after exposure to rats with interstitial pneumonia, ${ }^{58}$ similar to our observations. The lesions had a predictable time course and were attributed to a transmissible agent that was initially termed rat respiratory virus. Thirteen years later, this transmissible agent was identified as Pneumocystis. ${ }^{30,31}$

The morphometric parameters measured in this study were selected on the basis of their theoretical effects on respiratory physiology and the potential damage they may inflict on developing lungs. The thickness of the airway epithelium was measured because an increase in thickness of $0.5 \mu \mathrm{m}$ decreases the airway diameter by $1 \mu \mathrm{m}(0.5 \times 2)$ and, in a contracted state as in the expiration phase, these changes increase airway resistance by 300 times, according to the Poisseuille law. ${ }^{59}$ Meanwhile, excess airway mucus impairs mucociliary clearance and may favor mucus plugging, airway expiratory collapse, and ultimately shunting, with impaired airflow and ventilation/perfusion ratios. Therefore, the expression of Muc5ac was assessed as a marker of mucus production because it is a major mucin in pediatric airways. ${ }^{60}$ Epithelial thickening and excess mucus 
production were observed, both of which may cause airway narrowing and increase the possibility of airway collapse, especially when the intrathoracic pressure increases in the exhalation phase. ${ }^{61,62}$ In addition, the exocytosis of mucus from mucus granules packaged in goblet airway epithelial cells may expand their mucus volume by $>200$-fold in milliseconds, suggesting that narrow airways can become occluded in one breathing cycle. ${ }^{63}$

The Image Pro-Plus histologic analysis software used in this study was essential to determine the progression of epithelial thickening and airway narrowing, which are not necessarily noticeable by microscopy. In addition, examining the lung at a low magnification allowed us to observe focal damage, including the proportion of bronchioles and blood vessels surrounded by inflammatory cuffs. The significant increase in peribronchiolar and perivascular inflammatory cuffs in this study may translate into focal thickening of the air-blood interface, which might impair oxygen uptake and lead to local hypoxia. Transient hypoxemia was reported in Pneumocystis-infected immunocompetent mice and is an early and cardinal clinical sign of PCP. ${ }^{34}$ The peribronchiolar and perivascular cuffs were composed of mononuclear cells, particularly $\mathrm{CD} 4{ }^{+}$T-cell lymphocytes, which were prominent and appeared around the vessels before than around the bronchioles. This pulmonary response was related to $\mathrm{Th} 2$ activation, as shown by the increased levels of $\mathrm{Il13}$ and Gata3. The intensity of this type of inflammatory response is associated with deteriorated oxygenation and decreased survival in patients with PCP. ${ }^{34}$ It is also associated with an asthmalike pathology and airway hyperreactivity in mice intratracheally inoculated with Pneumocystis. ${ }^{2,47}$ The early innate immune response to Pneumocystis infection, which causes airway inflammation and hyperreactivity, can be influenced by the genetic background, as illustrated by differences in responses to infection between different inbred strains of mice. ${ }^{33,64}$ Therefore, the relative impact of this infection in the general population may differ between infants from different genetic backgrounds.

In conclusion, this study describes the histologic morphometry progression of lung disease and activation of selected immunological markers naturally acquired at birth during primary Pneumocystis infection in immunocompetent rats up to 75 days of age. The results are consistent with the findings in nonimmunosuppressed infants and with previous reports describing pathologic effects of Pneumocystis in nonimmunosuppressed adults and in different animal species, like rats, mice, and monkeys. ${ }^{2,11,31-34,55,56,58}$ Further elucidation of the pathogenesis of Pneumocystis infection in the nonimmunosuppressed host is warranted to understand the potential clinical relevance of these findings, particularly because of the high prevalence of primary Pneumocystis infection in young infants.

We raise the hypothesis that the primary Pneumocystis infection may adversely affect the respiratory physiology and the response to infections or other respiratory insults of the developing infant lung. The predictable epidemiology with a high prevalence of Pneumocystis in 2- to 5-month-old infants, ${ }^{11,12,14,16,21}$ plus the fact that the present results are consistent with those of prior studies in autopsied infants and in animal models documenting Pneumocystis-associated pathology, underlines the importance of testing this hypothesis. However, the inability to apply the Koch criteria for determining causality is challenging. This is determined by the high prevalence and asymptomatic features of the infection, precluding diagnosis and the identification of proper controls, ${ }^{65}$ and indicates that clinical trials assessing the effects of preventing Pneumocystis infection in infants may be performed as a proof-of-concept test of our hypothesis. $^{65}$

\section{Acknowledgments}

We thank Prof. Juan de Dios Escolar Castellón (University of Zaragoza, Zaragoza, Spain) for guidance on the morphometry determinations of the study and quantification of fibrosis; and Nelson Ponce (University of Chile School of Medicine, Santiago, Chile) for excellent animal care support.

\section{References}

1. Meissner HC: Viral bronchiolitis in children. N Engl J Med 2016, $374: 62-72$

2. Meissner NN, Swain S, Tighe M, Harmsen A: Role of type I IFNs in pulmonary complications of Pneumocystis murina infection. J Immunol 2005, 174:5462-5471

3. Holtzman MJ, Byers DE, Alexander-Brett J, Wang X: The role of airway epithelial cells and innate immune cells in chronic respiratory disease. Nat Rev Immunol 2014, 14:686-698

4. Holtzman MJ, Byers DE, Brett JA, Patel AC, Agapov E, Jin X, Wu K: Linking acute infection to chronic lung disease: the role of IL33-expressing epithelial progenitor cells. Ann Am Thorac Soc 2014, 11 Suppl 5:S287-S291

5. Siegle JS, Hansbro N, Herbert C, Rosenberg HF, Domachowske JB, Asquith KL, Foster PS, Kumar RK: Early-life viral infection and allergen exposure interact to induce an asthmatic phenotype in mice. Respir Res 2010, 11:14

6. Hall CB, Weinberg GA, Blumkin AK, Edwards KM, Staat MA, Schulz AF, Poehling KA, Szilagyi PG, Griffin MR, Williams JV, Zhu Y, Grijalva CG, Prill MM, Iwane MK: Respiratory syncytial virus-associated hospitalizations among children less than 24 months of age. Pediatrics 2013, 132:e341-e348

7. Stockman LJ, Curns AT, Anderson LJ, Fischer-Langley G: Respiratory syncytial virus-associated hospitalizations among infants and young children in the United States, 1997-2006. Pediatr Infect Dis J 2012, 31:5-9

8. Beard CB, Fox MR, Lawrence GG, Guarner J, Hanzlick RL, Huang L, Del Rio C, Rimland D, Duchin JS, Colley DG: Genetic differences in Pneumocystis isolates recovered from immunocompetent infants and from adults with AIDS: epidemiological implications. J Infect Dis 2005, 192:1815-1818

9. Ponce CA, Bustamante RI, Gallo M, Vargas SL: Diagnosis of the primary infection by Pneumocystis in autopsy specimens from two infants using lung impression smears (touch preps). Med Mycol Case Rep 2014, 5:28-31

10. Vargas SL, Hughes WT, Santolaya ME, Ulloa AV, Ponce CA, Cabrera CE, Cumsille F, Gigliotti F: Search for primary infection by 
Pneumocystis carinii in a cohort of normal, healthy infants. Clin Infect Dis 2001, 32:855-861

11. Vargas SL, Ponce CA, Gallo M, Perez F, Astorga JF, Bustamante R, Chabé M, Durand-Joly I, Iturra P, Miller RF, Aliouat EM, Dei-Cas E: Near-universal prevalence of Pneumocystis and associated increase in mucus in the lungs of infants with sudden unexpected death. Clin Infect Dis 2013, 56:171-179

12. Larsen HH, von Linstow ML, Lundgren B, Hogh B, Westh H, Lundgren JD: Primary Pneumocystis infection in infants hospitalized with acute respiratory tract infection. Emerg Infect Dis 2007, 13: 66-72

13. Simonds RJ, Oxtoby MJ, Caldwell MB, Gwinn ML, Rogers MF: Pneumocystis carinii pneumonia among US children with perinatally acquired HIV infection. JAMA 1993, 270:470-473

14. Vargas SL, Ponce CA, Galvez P, Ibarra C, Haas EA, Chadwick AE, Krous H: Pneumocystis is not a direct cause of sudden infant death syndrome. Pediatr Infect Dis J 2007, 26:81-83

15. Vargas SL, Ponce CA, Hughes WT, Wakefield AE, Weitz JC, Donoso S, Ulloa AV, Madrid P, Gould S, Latorre JJ, Avila R, Benveniste S, Gallo M, Belletti J, López R: Association of primary Pneumocystis carinii infection and sudden infant death syndrome. Clin Infect Dis 1999, 29:1489-1493

16. Vargas SL, Ponce CA, Luchsinger V, Silva C, Gallo M, Lopez R, Belletti J, Velozo L, Avila R, Palomino MA, Benveniste MA, Avendaño LF: Detection of Pneumocystis carinii f. sp. hominis and viruses in presumably immunocompetent infants who died in the hospital or in the community. J Infect Dis 2005, 191:122-126

17. Icenhour CR, Rebholz SL, Collins MS, Cushion MT: Early acquisition of Pneumocystis carinii in neonatal rats as evidenced by PCR and oral swabs. Eukaryot Cell 2002, 1:414-419

18. Vargas SL, Ponce CA, Sanchez CA, Ulloa AV, Bustamante R, Juarez G: Pregnancy and asymptomatic carriage of Pneumocystis jiroveci. Emerg Infect Dis 2003, 9:605-606

19. Kourtis AP, Read JS, Jamieson DJ: Pregnancy and infection. N Eng1 J Med 2014, 371:1077

20. Miller RF, Ambrose HE, Novelli V, Wakefield AE: Probable motherto-infant transmission of Pneumocystis carinii f. sp. hominis infection. J Clin Microbiol 2002, 40:1555-1557

21. Vera C, Aguilar YA, Velez LA, Rueda ZV: High transient colonization by Pneumocystis jirovecii between mothers and newborn. Eur J Pediatr 2017, 176:1619-1627

22. An CL, Gigliotti F, Harmsen AG: Exposure of immunocompetent adult mice to Pneumocystis carinii f. sp. muris by cohousing: growth of P. carinii f. sp. muris and host immune response. Infect Immun 2003, 71:2065-2070

23. Vargas SL, Hughes WT, Wakefield AE, Oz HS: Limited persistence in and subsequent elimination of Pneumocystis carinii from the lungs after P. carinii pneumonia. J Infect Dis 1995, 172:506-510

24. Vestereng VH, Bishop LR, Hernandez B, Kutty G, Larsen HH, Kovacs JA: Quantitative real-time polymerase chain-reaction assay allows characterization of Pneumocystis infection in immunocompetent mice. J Infect Dis 2004, 189:1540-1544

25. Ponce CA, Gallo M, Bustamante R, Vargas SL: Pneumocystis colonization is highly prevalent in the autopsied lungs of the general population. Clin Infect Dis 2010, 50:347-353

26. Garcia CA, Delpiano L, Prado F, Ponce CA, Amaya M, Vargas SL: [Severe apnea: an early sign of Pneumocystis carinii pneumonia in an HIV-negative infant] Spanish. Rev Med Chil 2000, 128:425-429

27. Heresi GP, Caceres E, Atkins JT, Reuben J, Doyle M: Pneumocystis carinii pneumonia in infants who were exposed to human immunodeficiency virus but were not infected: an exception to the AIDS surveillance case definition. Clin Infect Dis 1997, 25:739-740

28. Sheldon WH: Subclinical Pneumocystis pneumonitis. AMA J Dis Child 1959, 97:287-297

29. Perez FJ, Ponce CA, Rojas DA, Iturra PA, Bustamante RI, Gallo M, Hananias K, Vargas SL: Fungal colonization with Pneumocystis correlates to increasing chloride channel accessory 1 (hCLCA1) suggesting a pathway for up-regulation of airway mucus responses, in infant lungs. Results Immunol 2014, 4:58-61

30. Henderson KS, Dole V, Parker NJ, Momtsios P, Banu L, Brouillette R, Simon MA, Albers TM, Pritchett-Corning KR, Clifford CB, Shek WR: Pneumocystis carinii causes a distinctive interstitial pneumonia in immunocompetent laboratory rats that had been attributed to "rat respiratory virus". Vet Pathol 2012, 49: $440-452$

31. Livingston RS, Besch-Williford CL, Myles MH, Franklin CL, Crim MJ, Riley LK: Pneumocystis carinii infection causes lung lesions historically attributed to rat respiratory virus. Comp Med 2011, 61:45-59

32. Swain SD, Meissner N, Han S, Harmsen A: Pneumocystis infection in an immunocompetent host can promote collateral sensitization to respiratory antigens. Infect Immun 2011, 79:1905-1914

33. Swain SD, Meissner NN, Siemsen DW, McInnerney K, Harmsen AG: Pneumocystis elicits a STAT6-dependent, strainspecific innate immune response and airway hyperresponsiveness. Am J Respir Cell Mol Biol 2012, 46:290-298

34. Wright TW, Gigliotti F, Finkelstein JN, McBride JT, An CL, Harmsen AG: Immune-mediated inflammation directly impairs pulmonary function, contributing to the pathogenesis of Pneumocystis carinii pneumonia. J Clin Invest 1999, 104:1307-1317

35. Roths JB, Smith AL, Sidman CL: Lethal exacerbation of Pneumocystis carinii pneumonia in severe combined immunodeficiency mice after infection by pneumonia virus of mice. J Exp Med 1993, 177: $1193-1198$

36. Foster SB, McIntosh K, Thompson B, Lu M, Yin W, Rich KC, Mendez H, Serchuck LK, Diaz C, Paul ME, Shearer WT: Increased incidence of asthma in HIV-infected children treated with highly active antiretroviral therapy in the National Institutes of Health Women and Infants Transmission Study. J Allergy Clin Immunol 2008, 122:159-165

37. Eddens T, Campfield BT, Serody K, Manni ML, Horne W, Elsegeiny W, McHugh KJ, Pociask D, Chen K, Zheng M, Alcom JF, Wenzel S, Kolls JK: A novel CD4+ T cell-dependent murine model of Pneumocystis-driven asthma-like pathology. Am J Respir Crit Care Med 2016, 194:807-820

38. Hughes WT: Prevention and treatment of Pneumocystis carinii pneumonia. Annu Rev Med 1991, 42:287-295

39. Kling HM, Norris KA: Vaccine-induced immunogenicity and protection against Pneumocystis pneumonia in non-human primate model of HIV-pneumocystis co-infection. J Infect Dis 2016, 213: $1586-1595$

40. Tesini BL, Wright TW, Malone JE, Haidaris CG, Harber M, Sant AJ, Nayak JL, Gigliotti F: Immunization with Pcal protects mice against Pneumocystis pneumonia and generates antibody to Pneumocystis jirovecii. Infect Immun 2017, 85. e00850-16

41. Committee for the Update of the Guide for the Care and Use of Laboratory Animals; National Research Council: Guide for the Care and Use of Laboratory Animals: Eighth Edition. Washington, DC, National Academies Press, 2011

42. Edman JC, Edman U, Cao M, Lundgren B, Kovacs JA, Santi DV: Isolation and expression of the Pneumocystis carinii dihydrofolate reductase gene. Proc Natl Acad Sci U S A 1989, 86:8625-8629

43. Larsen HH, Kovacs JA, Stock F, Vestereng VH, Lundgren B, Fischer SH, Jill VJ: Development of a rapid real-time PCR assay for quantitation of Pneumocystis carinii f. sp. carinii. J Clin Microbiol 2002, 40:2989-2993

44. Lugade AA, Bogner PN, Thanavala Y: Murine model of chronic respiratory inflammation. Adv Exp Med Biol 2011, 780:125-141

45. O'Driscoll J, Ryan JP: A modified haematoxylin and eosin stain for histological sections of lymph nodes. J Clin Pathol 1978, 31:700

46. Escolar JD, Tejero C, Escolar MA, Montalvo F, Garisa R: Methodological contributions for the morphometric study of the lung: approximation to the ideal sample size and quantification of collagen fiber. Anat Rec 1997, 247:501-511 
47. Cohn L, Homer RJ, MacLeod H, Mohrs M, Brombacher F, Bottomly K: Th2-induced airway mucus production is dependent on IL-4Ralpha, but not on eosinophils. J Immunol 1999, 162:6178-6183

48. Wang J, Gigliotti F, Maggirwar S, Johnston C, Finkelstein JN, Wright TW: Pneumocystis carinii activates the NF-kappaB signaling pathway in alveolar epithelial cells. Infect Immun 2005, 73: $2766-2777$

49. Wang J, Gigliotti F, Bhagwat SP, George TC, Wright TW: Immune modulation with sulfasalazine attenuates immunopathogenesis but enhances macrophage-mediated fungal clearance during Pneumocystis pneumonia. PLoS Pathog 2010, 6:e1001058

50. Damiani C, Le Gal S, Lejeune D, Brahimi N, Virmaux M, Nevez G, Totet A: Serum (1->3)-beta-D-glucan levels in primary infection and pulmonary colonization with Pneumocystis jirovecii. J Clin Microbiol 2011, 49:2000-2002

51. Vicencio AG, Santiago MT, Tsirilakis K, Stone A, Worgall S, Foley EA, Bush D, Goldman DL: Fungal sensitization in childhood persistent asthma is associated with disease severity. Pediatr Pulmonol 2014, 49:8-14

52. Le TT, Karmouty-Quintana H, Melicoff E, Weng T, Chen NY, Pedroza M, Zhou Y, Davies J, Philip K, Molina J, Luo F, George AT, Garcia-Morales LJ, Bunge RR, Bruckner BA, Loebe M, Seethamraju H, Agarwal SK, Blackburn MR: Blockade of IL-6 trans signaling attenuates pulmonary fibrosis. J Immunol 2014, 193: $3755-3768$

53. Tatler AL, Jenkins G: TGF-beta activation and lung fibrosis. Proc Am Thorac Soc 2012, 9:130-136

54. Leibovitz E, Rigaud M, Pollack H, Lawrence R, Chandwani S, Krasinski K, Borkowsky W: Pneumocystis carinii pneumonia in infants infected with the human immunodeficiency virus with more than $450 \mathrm{CD} 4 \mathrm{~T}$ lymphocytes per cubic millimeter. N Engl J Med 1990, 323:531-533

55. Morris A, Sciurba FC, Lebedeva IP, Githaiga A, Elliott WM, Hogg JC, Huang L, Norris K: Association of chronic obstructive pulmonary disease severity and Pneumocystis colonization. Am J Respir Crit Care Med 2004, 170:408-413

56. Shipley TW, Kling HM, Morris A, Patil S, Kristoff J, Guyach SE, Murphy JE, Shao X, Sciurba FC, Rogers RM, Richards T, Thompson P, Montelaro RC, Coxson HO, Hogg JC, Norris KA: Persistent Pneumocystis colonization leads to the development of chronic obstructive pulmonary disease in a nonhuman primate model of AIDS. J Infect Dis 2010, 202:302-312

57. Kling HM, Shipley TW, Guyach S, Tarantelli R, Morris A, Norris KA: Trimethoprim-sulfamethoxazole treatment does not reverse obstructive pulmonary changes in pneumocystis-colonized nonhuman primates with SHIV infection. J Acquir Immune Defic Syndr 2014, 65:381-389

58. Albers TM, Simon MA, Clifford CB: Histopathology of naturally transmitted "rat respiratory virus": progression of lesions and proposed diagnostic criteria. Vet Pathol 2009, 46:992-999

59. Lai HY, Rogers DF: Mucus hypersecretion in asthma: intracellular signalling pathways as targets for pharmacotherapy. Curr Opin Allergy Clin Immunol 2010, 10:67-76

60. Rogers DF: Pulmonary mucus: pediatric perspective. Pediatr Pulmonol 2003, 36:178-188

61. Bramson RT, Griscom NT, Cleveland RH: Interpretation of chest radiographs in infants with cough and fever. Radiology 2005, 236: 22-29

62. Heil M, Hazel AL, Smith JA: The mechanics of airway closure. Respir Physiol Neurobiol 2008, 163:214-221

63. Verdugo P: Mucin exocytosis. Am Rev Respir Dis 1991, 144: S33-S37

64. Limper AH, Offord KP, Smith TF, Martin WJ 2nd: Pneumocystis carinii pneumonia: differences in lung parasite number and inflammation in patients with and without AIDS. Am Rev Respir Dis 1989, 140:1204-1209

65. Inglis TJ: Principia aetiologica: taking causality beyond Koch's postulates. J Med Microbiol 2007, 56:1419-1422 